\title{
Blood pressure percentiles by age and height for non-overweight Chinese children and adolescents: analysis of the china health and nutrition surveys 1991-2009
}

\author{
Weili Yan ${ }^{1 *}$, Fang Liu ${ }^{2}$, Xuesong Li ${ }^{3}$, Lin Wu' ${ }^{2}$, Yi Zhang ${ }^{1}$, Yi Cheng ${ }^{1}$, Wenhao Zhou ${ }^{4}$ and Guoying Huang ${ }^{2}$
}

\begin{abstract}
Background: Hypertension is an important health problem in China and raised blood pressure in children may lead to future hypertension. Accordingly we aimed to provide a reference blood pressure table for age, gender and height in Chinese children.

Methods: A reference sample of subjects was drawn from the Chinese Health and National Survey 1999-2009 aged 7-17 years after excluding overweight and obese children, the 50th, 90th and 95th percentiles of systolic and diastolic blood pressure (SBP and DBP)are presented corrected for height and age by gender. These values are compared with existing Chinese and US recommendations.

Results: Results for the 50th, 90th and 95th percentile of SBP and DBP for 6245 boys and 5707 girls were presented by age and height percentiles. These observations were lower than existing Chinese recommendations before 13 years of age at median heightbut went higher in those $>13$ years old. At same age and height, SBP levels of American children were overall higher than Chinese counterparts from this study by average 9-10 $\mathrm{mm} \mathrm{Hg}$, but DBP did not show overall or significant difference.
\end{abstract}

Conclusions: The first height-specific blood pressure reference values are proposed for Chinese children and adolescents aged 7-17 years. These are lower than existing US reference values and current Chinese cutoffs.

Keywords: Adolescents, Blood pressure, Hypertension, Prevention, Reference

\section{Background}

High blood pressure in children and adolescents is more common and is associated with increasing childhood obesity in western countries [1-3] as well as in China $[4,5]$. Prehypertension and hypertension in childhood are associated with a 2.5 fold increase likelihood of adult hypertension [6,7]. In addition, childhood hypertension correlates with early atherosclerosis, impaired arterial compliance [8-10], cardiac structural changes [11], and additional risk factors for metabolic syndrome. In a recent longitudinal study of 342 children aged 11-15 years, childhood BP was found to predict early adulthood

\footnotetext{
* Correspondence: yanwl@fudan.edu.cn

'Department of Clinical Epidemiology, Children's Hospital of Fudan

University, 399 Wanyuan Road, Shanghai 201102, China

Full list of author information is available at the end of the article
}

dyslipidaemia, independently of body mass index (BMI) [12]. For the pediatric population, the percentile of blood pressure is used since blood pressure changes with age and body size. The 90th and 95th percentiles of blood pressure by age and height are recommended by the fourth report on the diagnosis, evaluation and treatment of high blood pressure in children and adolescents to define prehypertension and hypertension respectively [13]. National blood pressure cutoffs by age groups for Chinese children were first published in 1992, and updated in 2010 [14], however, height was not taken into account in either of them. In order to achieve more accurate blood pressure evaluation in children, the aim of this study is to establish mercury blood pressure reference values by age and height Chinese children and adolescents aged 7-17 years based on the 
nationally representative study sample, China Health and Nutrition Survey (CHNS).

\section{Methods}

We used data from the China Health and Nutrition Survey (CHNS) [15-17]. General information, methods and dataset information can be accessed from the website (http://www.cpc.unc.edu/projects/china) [15-17]. Briefly, participants were sampled from seven Chinese provinces (namely Jiangsu, Shandong, Henan, Hubei, Human, Guangxi and Guizhou). The survey design and methods have been described in detail elsewhere previously $[16,17]$. After exclusion of overweight and obese students based on the Chinese recommendation [18], boys and girls aged 7-17 years were included in this analysis. The University of North Carolina and the China Center for Disease Control and Prevention had reviewed and approved the procedures for data collection and all subjects and/or their parents/guardians have provided written informed consent.

\section{Measurements and definitions}

Blood pressure was measured using mercury sphygmomanometer according to the standard protocol by trained and qualified observers, which was described elsewhere [5]. Korotkoff phase 1 and Korotkoff phase 5 were used for defining systolic blood pressure (SBP) and diastolic blood pressure (DBP). Appropriate size of cuff was used to measure blood pressure for children using the right arm. The mean of 2 measurements was analyzed. Height and weight were measured to calculate body mass index (BMI, weight in kilograms divided by the square of height in meters). Overweight and obese were defined according to the age- and gender-specific BMI reference standard for Chinese children and adolescents [18].

\section{Statistical methods}

Percentiles of height as a function of age were obtained by smoothed centile curves modeled using LMS method [19] with the program LMSChartMaker Pro 2.3. The reference curves of blood pressure by age and height were simultaneously fitted by using an extension of the LMS method [19], namely the generalized additive model for location scale and shape (GAMLSS) with the Box-Cox power exponential (BCPE) distribution family or BOXCOC-t, fitted with GAMLSS 4.1-5 in the free statistical software R2.15.0 (http://www.cran.r-project.org/). GAMLSS is a generalization of the LMS method where $Y$ has a specified frequency distribution $\mathrm{D}(\mu, \sigma, v, \tau)$, the 4 parameters define the location, scale and shape of the blood pressure distribution with age and height. Linear effect and additive effect of age and height (two covariates) on SBP and DBP were modeled simultaneously to obtain the optimal models by minimizing the Schwarz Bayesian Criterion
(SBC). The all possible functions of age and height as well as the interactions of which were considered in the modeling, the most fitted model were achieved. The reference values of 50th, 90th, and 95th percentiles of SBP and DBP were computed by age and height (exact heights according to the 5th, 25th, 50th, 75th and 95th percentiles) for boys and girls respectively.

To make comparisons with the existing Chinese blood pressure recommendations for children [14], heights and BMI were standardized according to the same reference populations, the Chinese National Survey on Constitution and Health (CNSCH 2005) [20]. Since height percentiles were not considered in the existing recommendation [14], blood pressure reference values with median height of this study were used to make comparisons.

Differences in proposed SBP and DBP cutoff values (the 50th, 90th and 95th percentiles) for Chinese boys and girls were compared with the Fourth Report on the Diagnosis, Evaluation, and Treatment of High Blood Pressure in Children and Adolescents of the US [13] at

Table 1 Baseline characteristics of the reference population of nonoverweight

\begin{tabular}{|c|c|c|c|}
\hline & \multicolumn{3}{|c|}{ Age, yrs } \\
\hline & $7-10$ & $11-13$ & 14-17 \\
\hline \multicolumn{4}{|c|}{ Children excluded because of overweight/obese, $n$} \\
\hline Boys & 127 & 138 & 128 \\
\hline Girls & 134 & 156 & 127 \\
\hline \multicolumn{4}{|c|}{ Children included, $\mathrm{n}$} \\
\hline Boys & 1755 & 2775 & 2294 \\
\hline Girls & 1656 & 2517 & 2074 \\
\hline \multicolumn{4}{|c|}{ Weight, kg } \\
\hline Boys & $25.0 \pm 5.3$ & $35.7 \pm 9.1$ & $51.2 \pm 9.6$ \\
\hline Girls & $24.1 \pm 5.1$ & $35.6 \pm 8.5$ & $47.4 \pm 7.2$ \\
\hline \multicolumn{4}{|c|}{ Height, cm } \\
\hline Boys & $125.1 \pm 8.4$ & $143.0 \pm 11.1$ & $163.3 \pm 8.9$ \\
\hline Girls & $124.1 \pm 8.8$ & $143.7 \pm 10.2$ & $155.8 \pm 6.8$ \\
\hline \multicolumn{4}{|c|}{ Height range, $\mathrm{cm}$} \\
\hline Boys & 101.8-153.0 & $96.0-178.0$ & 130.6-189.0 \\
\hline Girls & $98.0-152.3$ & 115.0-171.5 & 130.0-180.5 \\
\hline \multicolumn{4}{|c|}{ BMI, kg/m² } \\
\hline Boys & $15.2 \pm 1.3$ & $16.6 \pm 1.8$ & $18.9 \pm 2.0$ \\
\hline Girls & $14.9 \pm 1.3$ & $16.6 \pm 2.0$ & $19.1 \pm 2.0$ \\
\hline \multicolumn{4}{|c|}{$\mathrm{SBP}, \mathrm{mm} \mathrm{Hg}$} \\
\hline Boys & $90.7 \pm 11.9$ & $96.4 \pm 11.7$ & $106.7 \pm 12.4$ \\
\hline Girls & $89.8 \pm 11.4$ & $96.6 \pm 12.0$ & $104.0 \pm 10.7$ \\
\hline \multicolumn{4}{|c|}{$\mathrm{DBP}, \mathrm{mm} \mathrm{Hg}$} \\
\hline Boys & $59.7 \pm 9.4$ & $63.4 \pm 8.8$ & $69.4 \pm 9.3$ \\
\hline Girls & $58.9 \pm 9.6$ & $63.4 \pm 8.9$ & $68.6 \pm 8.1$ \\
\hline
\end{tabular}

Children and Adolescents ( 6245 boys and 5704 girls aged 7-17 yrs). 
Table 2 Age-height-specific references: median, the 90th and 95th percentiles of SBP and DBP values for boys aged 7-17 years

\begin{tabular}{|c|c|c|c|c|c|c|c|c|c|c|}
\hline \multirow[t]{2}{*}{ Age, years } & \multirow[t]{2}{*}{ Height, cm } & \multirow[t]{2}{*}{ Percentiles of height } & \multicolumn{4}{|c|}{ SBP percentiles, $\mathrm{mm} \mathrm{Hg}$} & \multicolumn{4}{|c|}{$\mathrm{DBP}, \mathrm{mm} \mathrm{Hg}$} \\
\hline & & & $\mathbf{s}^{*}$ & 50th & 90th & 95th & $s^{*}$ & 50th & 90th & 95th \\
\hline 7 & 109.0 & 5 th & 0.13 & 82 & 96 & 101 & 0.16 & 55 & 67 & 70 \\
\hline 7 & 115.0 & 25th & 0.12 & 84 & 99 & 104 & 0.16 & 56 & 68 & 71 \\
\hline 7 & 120.0 & 50th & 0.12 & 86 & 101 & 106 & 0.16 & 57 & 69 & 72 \\
\hline 7 & 125.0 & 75th & 0.12 & 88 & 103 & 108 & 0.15 & 59 & 70 & 74 \\
\hline 7 & 130.0 & 95th & 0.12 & 90 & 105 & 110 & 0.15 & 60 & 71 & 75 \\
\hline 8 & 113.7 & 5 th & 0.12 & 84 & 99 & 103 & 0.16 & 56 & 68 & 71 \\
\hline 8 & 119.5 & 25th & 0.12 & 86 & 101 & 105 & 0.15 & 58 & 69 & 72 \\
\hline 8 & 124.5 & 50th & 0.12 & 88 & 103 & 108 & 0.15 & 59 & 70 & 73 \\
\hline 8 & 128.2 & 75th & 0.12 & 90 & 105 & 109 & 0.15 & 60 & 71 & 74 \\
\hline 8 & 135.4 & 95th & 0.12 & 92 & 107 & 112 & 0.15 & 61 & 73 & 76 \\
\hline 9 & 119.5 & 5 th & 0.12 & 87 & 101 & 106 & 0.15 & 58 & 69 & 72 \\
\hline 9 & 125.4 & 25th & 0.12 & 89 & 104 & 108 & 0.15 & 59 & 70 & 74 \\
\hline 9 & 130.0 & 50th & 0.12 & 91 & 105 & 110 & 0.15 & 60 & 72 & 75 \\
\hline 9 & 135.1 & 75th & 0.12 & 93 & 107 & 112 & 0.15 & 61 & 73 & 76 \\
\hline 9 & 143.0 & 95th & 0.11 & 96 & 111 & 115 & 0.14 & 63 & 75 & 78 \\
\hline 10 & 122.0 & 5 th & 0.12 & 88 & 102 & 107 & 0.15 & 58 & 70 & 73 \\
\hline 10 & 129.0 & 25th & 0.12 & 91 & 105 & 110 & 0.15 & 60 & 71 & 75 \\
\hline 10 & 134.0 & 50th & 0.12 & 92 & 107 & 112 & 0.14 & 61 & 72 & 76 \\
\hline 10 & 140.0 & 75th & 0.11 & 95 & 110 & 114 & 0.14 & 62 & 74 & 77 \\
\hline 10 & 146.4 & 95th & 0.11 & 97 & 112 & 117 & 0.14 & 64 & 75 & 79 \\
\hline 11 & 126.7 & 5th & 0.12 & 90 & 104 & 109 & 0.15 & 60 & 71 & 74 \\
\hline 11 & 134.0 & 25th & 0.12 & 93 & 107 & 112 & 0.14 & 61 & 72 & 76 \\
\hline 11 & 139.3 & 50th & 0.11 & 95 & 109 & 114 & 0.14 & 62 & 74 & 77 \\
\hline 11 & 144.6 & 75th & 0.11 & 97 & 112 & 116 & 0.14 & 64 & 75 & 78 \\
\hline 11 & 153.0 & 95th & 0.11 & 100 & 115 & 119 & 0.13 & 66 & 77 & 80 \\
\hline 12 & 133.0 & 5 th & 0.11 & 93 & 107 & 111 & 0.14 & 61 & 72 & 75 \\
\hline 12 & 139.5 & 25th & 0.11 & 95 & 110 & 114 & 0.14 & 63 & 74 & 77 \\
\hline 12 & 145.5 & 50th & 0.11 & 97 & 112 & 116 & 0.13 & 64 & 75 & 78 \\
\hline 12 & 152.0 & 75th & 0.11 & 100 & 115 & 119 & 0.13 & 66 & 77 & 80 \\
\hline 12 & 162.0 & 95th & 0.11 & 104 & 119 & 123 & 0.13 & 68 & 79 & 82 \\
\hline 13 & 135.0 & 5 th & 0.11 & 94 & 108 & 112 & 0.14 & 62 & 73 & 76 \\
\hline 13 & 145.0 & 25th & 0.11 & 98 & 112 & 116 & 0.13 & 64 & 75 & 78 \\
\hline 13 & 152.0 & 50th & 0.11 & 100 & 115 & 119 & 0.13 & 66 & 77 & 80 \\
\hline 13 & 158.1 & 75th & 0.11 & 103 & 117 & 122 & 0.13 & 67 & 78 & 81 \\
\hline 13 & 168.1 & 95th & 0.10 & 106 & 121 & 126 & 0.12 & 69 & 80 & 84 \\
\hline 14 & 142.0 & 5th & 0.11 & 97 & 111 & 115 & 0.13 & 64 & 74 & 78 \\
\hline 14 & 152.0 & 25th & 0.11 & 101 & 115 & 119 & 0.13 & 66 & 77 & 80 \\
\hline 14 & 159.5 & 50th & 0.11 & 103 & 118 & 122 & 0.13 & 68 & 78 & 82 \\
\hline 14 & 165.0 & 75th & 0.10 & 106 & 120 & 125 & 0.12 & 69 & 80 & 83 \\
\hline 14 & 172.5 & 95th & 0.10 & 108 & 123 & 128 & 0.12 & 70 & 81 & 85 \\
\hline 15 & 147.9 & 5th & 0.11 & 99 & 114 & 118 & 0.13 & 65 & 76 & 79 \\
\hline 15 & 157.0 & 25th & 0.11 & 103 & 117 & 121 & 0.12 & 67 & 78 & 81 \\
\hline
\end{tabular}


Table 2 Age-height-specific references: median, the 90th and 95th percentiles of SBP and DBP values for boys aged 7-17 years (Continued)

\begin{tabular}{lllllllllll}
\hline 15 & 163.0 & 50 th & 0.10 & 105 & 120 & 124 & 0.12 & 68 & 79 & 82 \\
15 & 168.3 & 75 th & 0.10 & 107 & 122 & 126 & 0.12 & 70 & 80 & 84 \\
15 & 175.0 & 95 th & 0.10 & 110 & 124 & 129 & 0.12 & 71 & 82 & 85 \\
16 & 153.0 & 5 th & 0.11 & 102 & 116 & 120 & 0.12 & 66 & 77 & 80 \\
16 & 160.5 & 25 th & 0.10 & 104 & 119 & 123 & 0.12 & 68 & 79 & 82 \\
16 & 165.0 & 50 th & 0.10 & 106 & 121 & 125 & 0.12 & 69 & 80 & 83 \\
16 & 170.0 & 75 th & 0.10 & 108 & 123 & 127 & 0.12 & 70 & 81 & 84 \\
16 & 177.0 & 95 th & 0.10 & 111 & 125 & 130 & 0.12 & 72 & 83 & 86 \\
17 & 155.0 & 5 th & 0.10 & 103 & 117 & 121 & 0.12 & 67 & 78 & 80 \\
17 & 163.0 & 25 th & 0.10 & 106 & 120 & 124 & 0.12 & 69 & 79 & 82 \\
17 & 167.5 & 50 th & 0.10 & 107 & 122 & 126 & 0.12 & 70 & 80 & 83 \\
17 & 172.0 & 75 th & 0.10 & 109 & 124 & 128 & 0.12 & 71 & 81 & 84 \\
17 & 180.0 & 95 th & 0.10 & 112 & 127 & 131 & 0.11 & 73 & 83 & 86 \\
\hline
\end{tabular}

Notes

SBP, systolic blood pressure; DBP, diastolic blood pressure.

${ }^{*} \mathrm{~S}$, the coefficient of variation of blood pressure.

given age (7-17 years) and the median height $(\mathrm{cm})$. Since the height distributions of the two reference samples are not comparable, it is difficult to compare the corresponding height-depended 50th, 90th and 95th blood pressure percentiles directly, therefore, the expected SBP and DBP of US counterparts with the median height of Chinese reference population were computed based on the equations. For example, the 50th, 90th and 95th percentiles of SBP and DBP for an US boy aged 7 with the median height of $120 \mathrm{~cm}$, were calculated as 97, 111, $118 \mathrm{~mm} \mathrm{Hg}$ as well as 57,72 , and $80 \mathrm{~mm} \mathrm{Hg}$, based on the US equation [13] presented in the table B1 of the Fourth report [13]. Stata 11.0 (StataCorp LP, StataCorp, Texas 77845 USA) were used for conventional descriptive analysis.

Independent software called "Blood Pressure Calculator "has been developed based on the fitted models of blood pressure from this study.

\section{Results}

Based on Chinese national BMI cutoff points, a total of 620 boys and 445 girls $(8.2 \%)$ were excluded from the original study sample $(n=13014)$ because of being overweight or obese. The remaining reference sample consists of children and adolescents aged 7-17 years (including 6245 boys and 5704 girls) with complete data on age, gender, height and three SBP and DBP readings. The characteristics of subjects were given in Table 1 . It shows that the mean body weight, height, BMI, SBP and DBP increase with the age groups, the ranges of height for the three age groups vary from $50.5 \mathrm{~cm}$ to $58.4 \mathrm{~cm}$.

The optimal models for the 4 parameters of SBP and DBP distribution for boys and girls were fitted. It showed that BCPE model was the best fitted model for SBP for boys and DBP for both genders, BCT model was the best fitted model for SBP of girls. Reference values of the 50th, 90th, and 95th percentiles of SBP and DBP, were computed by age and exact heights according to the 5th, 25th, 50th, 75th and 95th percentiles ) for boys and girls respectively and presented as Table 2 (for boys) and Table 3 (for girls). At adolescents aged 17 years old with the median height $(167.5 \mathrm{~cm}$ for boys and $157.8 \mathrm{~cm}$ for girls), the median SBP were 107 for boys and 105 for girls; the 90th percentiles of SBP and DBP were $122 \mathrm{~mm}$ $\mathrm{Hg}$ and $80 \mathrm{~mm} \mathrm{Hg}$ for boys and $118 \mathrm{~mm} \mathrm{Hg}$ and $79 \mathrm{~mm}$ $\mathrm{Hg}$ for girls respectively, which were very close to the cutoff of $120 / 80 \mathrm{~mm} \mathrm{Hg}$ for identifying prehypertension for all ages recommended by the fourth report [13]. The 95th percentile of SBP and DBP were $126 \mathrm{~mm} \mathrm{Hg}$ and $83 \mathrm{~mm} \mathrm{Hg}$ for boys, and $122 \mathrm{~mm} \mathrm{Hg}$ and $82 \mathrm{~mm} \mathrm{Hg}$ for girls respectively, which are lower than the recommended optimal blood pressure of 130/85 mm Hg for adults [21].

\section{Comparison with available Chinese reference blood pressure tables}

Figure 1 showed the 90th percentiles of SBP and DBP for boys and girls aged 7-17 years by the 5th, 50th and 95th percentiles of height compared with that from the study by Mi J et al. [14]. It showed that SBP values for children at all ages with the median height proposed by this study were $5-10 \mathrm{~mm} \mathrm{Hg}$ lower. DBP was $2-3 \mathrm{~mm}$ $\mathrm{Hg}$ higher before age of 14, but tended to be similar afterwards. As shown in Figure 2, the reference sample of current study is shorter (0.88 SD for boys and 0.7 SD for girls) and thinner (0.68 SD for boys and 0.47 SD for 
Table 3 Age-height-specific references: median, the 90th and 95th percentiles of SBP and DBP values for girls aged 7-17 years

\begin{tabular}{|c|c|c|c|c|c|c|c|c|c|c|}
\hline \multirow[t]{2}{*}{ Age, years } & \multirow[t]{2}{*}{ Height, $\mathrm{cm}$} & \multirow[t]{2}{*}{ Percentile of height } & \multicolumn{4}{|c|}{$\mathrm{SBP}, \mathrm{mm} \mathrm{Hg}$} & \multicolumn{4}{|c|}{$\mathrm{DBP}, \mathrm{mm} \mathrm{Hg}$} \\
\hline & & & $\mathbf{s}^{*}$ & 50th & 90th & 95th & $s^{*}$ & 50th & 90th & 95th \\
\hline 7 & 108.0 & 5 th & 0.12 & 82 & 96 & 100 & 0.14 & 54 & 64 & 67 \\
\hline 7 & 114.2 & 25 th & 0.12 & 84 & 98 & 103 & 0.14 & 56 & 66 & 69 \\
\hline 7 & 118.2 & 50th & 0.12 & 86 & 100 & 104 & 0.14 & 56 & 67 & 70 \\
\hline 7 & 122.0 & 75th & 0.12 & 87 & 101 & 105 & 0.14 & 57 & 68 & 71 \\
\hline 7 & 129.6 & 95th & 0.12 & 89 & 103 & 108 & 0.14 & 59 & 70 & 73 \\
\hline 8 & 113.2 & 5 th & 0.12 & 85 & 99 & 103 & 0.14 & 56 & 66 & 69 \\
\hline 8 & 119.3 & 25th & 0.12 & 87 & 101 & 105 & 0.14 & 57 & 67 & 70 \\
\hline 8 & 123.0 & 50th & 0.12 & 88 & 102 & 106 & 0.14 & 58 & 68 & 71 \\
\hline 8 & 128.5 & 75th & 0.12 & 89 & 104 & 108 & 0.14 & 59 & 70 & 72 \\
\hline 8 & 135.0 & 95th & 0.11 & 91 & 106 & 110 & 0.14 & 60 & 71 & 74 \\
\hline 9 & 119.0 & 5 th & 0.12 & 87 & 101 & 105 & 0.14 & 57 & 68 & 70 \\
\hline 9 & 124.5 & 25th & 0.12 & 89 & 103 & 107 & 0.14 & 59 & 69 & 72 \\
\hline 9 & 130.0 & 50th & 0.11 & 91 & 105 & 109 & 0.14 & 60 & 70 & 73 \\
\hline 9 & 134.8 & 75th & 0.11 & 92 & 106 & 110 & 0.14 & 61 & 71 & 74 \\
\hline 9 & 143.0 & 95th & 0.11 & 95 & 109 & 113 & 0.14 & 62 & 73 & 76 \\
\hline 10 & 123.0 & 5 th & 0.12 & 89 & 103 & 107 & 0.13 & 59 & 69 & 72 \\
\hline 10 & 219.6 & 25th & 0.09 & 119 & 133 & 137 & 0.13 & 78 & 92 & 95 \\
\hline 10 & 135.2 & 50th & 0.11 & 93 & 107 & 111 & 0.13 & 61 & 72 & 75 \\
\hline 10 & 140.0 & 75th & 0.11 & 94 & 108 & 112 & 0.13 & 62 & 73 & 76 \\
\hline 10 & 148.0 & 95th & 0.11 & 97 & 111 & 115 & 0.13 & 64 & 75 & 78 \\
\hline 11 & 128.0 & 5th & 0.11 & 91 & 105 & 109 & 0.13 & 60 & 70 & 73 \\
\hline 11 & 135.0 & 25th & 0.11 & 94 & 107 & 111 & 0.13 & 62 & 72 & 75 \\
\hline 11 & 141.1 & 50th & 0.11 & 95 & 109 & 113 & 0.13 & 63 & 73 & 76 \\
\hline 11 & 147.7 & 75th & 0.11 & 97 & 111 & 115 & 0.13 & 64 & 75 & 78 \\
\hline 11 & 156.0 & 95th & 0.10 & 100 & 114 & 118 & 0.13 & 66 & 77 & 80 \\
\hline 12 & 132.6 & 5 th & 0.11 & 94 & 107 & 111 & 0.12 & 62 & 72 & 74 \\
\hline 12 & 142.0 & 25 th & 0.11 & 96 & 110 & 114 & 0.12 & 63 & 74 & 77 \\
\hline 12 & 147.0 & 50th & 0.11 & 98 & 112 & 116 & 0.12 & 64 & 75 & 78 \\
\hline 12 & 153.0 & 75th & 0.10 & 100 & 114 & 118 & 0.12 & 66 & 76 & 79 \\
\hline 12 & 159.4 & 95th & 0.10 & 102 & 116 & 120 & 0.12 & 67 & 78 & 81 \\
\hline 13 & 138.2 & 5 th & 0.11 & 96 & 109 & 113 & 0.12 & 63 & 73 & 76 \\
\hline 13 & 146.3 & 25th & 0.10 & 98 & 112 & 116 & 0.12 & 65 & 75 & 78 \\
\hline 13 & 151.2 & 50th & 0.10 & 100 & 114 & 118 & 0.12 & 66 & 76 & 79 \\
\hline 13 & 156.1 & 75th & 0.10 & 101 & 115 & 119 & 0.12 & 67 & 77 & 80 \\
\hline 13 & 162.0 & 95th & 0.10 & 103 & 117 & 121 & 0.12 & 68 & 79 & 82 \\
\hline 14 & 143.0 & 5 th & 0.10 & 98 & 112 & 116 & 0.12 & 65 & 75 & 77 \\
\hline 14 & 150.0 & 25th & 0.10 & 100 & 114 & 118 & 0.12 & 66 & 76 & 79 \\
\hline 14 & 154.2 & 50th & 0.10 & 102 & 115 & 119 & 0.12 & 67 & 77 & 80 \\
\hline 14 & 158.9 & 75th & 0.10 & 103 & 117 & 121 & 0.12 & 68 & 78 & 81 \\
\hline 14 & 165.0 & 95th & 0.10 & 105 & 118 & 122 & 0.12 & 69 & 80 & 83 \\
\hline 15 & 144.2 & 5th & 0.10 & 99 & 113 & 116 & 0.11 & 65 & 75 & 78 \\
\hline 15 & 151.0 & 25th & 0.10 & 101 & 115 & 119 & 0.11 & 67 & 77 & 80 \\
\hline
\end{tabular}


Table 3 Age-height-specific references: median, the 90th and 95th percentiles of SBP and DBP values for girls aged 7-17 years (Continued)

\begin{tabular}{lllllllllll}
\hline 15 & 155.6 & 50 th & 0.10 & 103 & 116 & 120 & 0.11 & 68 & 78 & 81 \\
15 & 160.0 & 75 th & 0.10 & 104 & 117 & 121 & 0.11 & 68 & 79 & 82 \\
15 & 165.8 & 95 th & 0.10 & 106 & 119 & 123 & 0.11 & 70 & 80 & 83 \\
16 & 145.8 & 5 th & 0.10 & 100 & 114 & 118 & 0.11 & 66 & 76 & 79 \\
16 & 152.9 & 25 th & 0.10 & 102 & 116 & 120 & 0.11 & 67 & 77 & 80 \\
16 & 157.0 & 50 th & 0.10 & 104 & 117 & 121 & 0.11 & 68 & 78 & 81 \\
16 & 161.0 & 75 th & 0.10 & 105 & 118 & 122 & 0.11 & 69 & 79 & 82 \\
16 & 167.6 & 95 th & 0.09 & 107 & 120 & 124 & 0.11 & 70 & 81 & 84 \\
17 & 145.6 & 5 th & 0.10 & 101 & 114 & 118 & 0.11 & 66 & 76 & 79 \\
17 & 153.1 & 25 th & 0.10 & 103 & 116 & 120 & 0.11 & 68 & 78 & 80 \\
17 & 157.8 & 50 th & 0.09 & 105 & 118 & 122 & 0.11 & 69 & 79 & 82 \\
17 & 162.4 & 75 th & 0.09 & 106 & 119 & 123 & 0.11 & 70 & 80 & 83 \\
17 & 168.0 & 95 th & 0.09 & 108 & 121 & 125 & 0.11 & 71 & 81 & 84 \\
\hline
\end{tabular}

Notes

SBP, systolic blood pressure; DBP, diastolic blood pressure.

${ }^{*} s$, the coefficient of variation of blood pressure.

girls) compared with the reference sample used by national recommendation [14] than the reference sample used the earlier study [14].

Height is not taken into account in the earlier national recommendation. The 50th, 90th and 95th centile curves of SBP proposed by the current study were lower than the existing national non-height specific reference, the differences tended to decrease after 14 years old. However, the three centile curves of the current study were lower than then existing national reference curves before

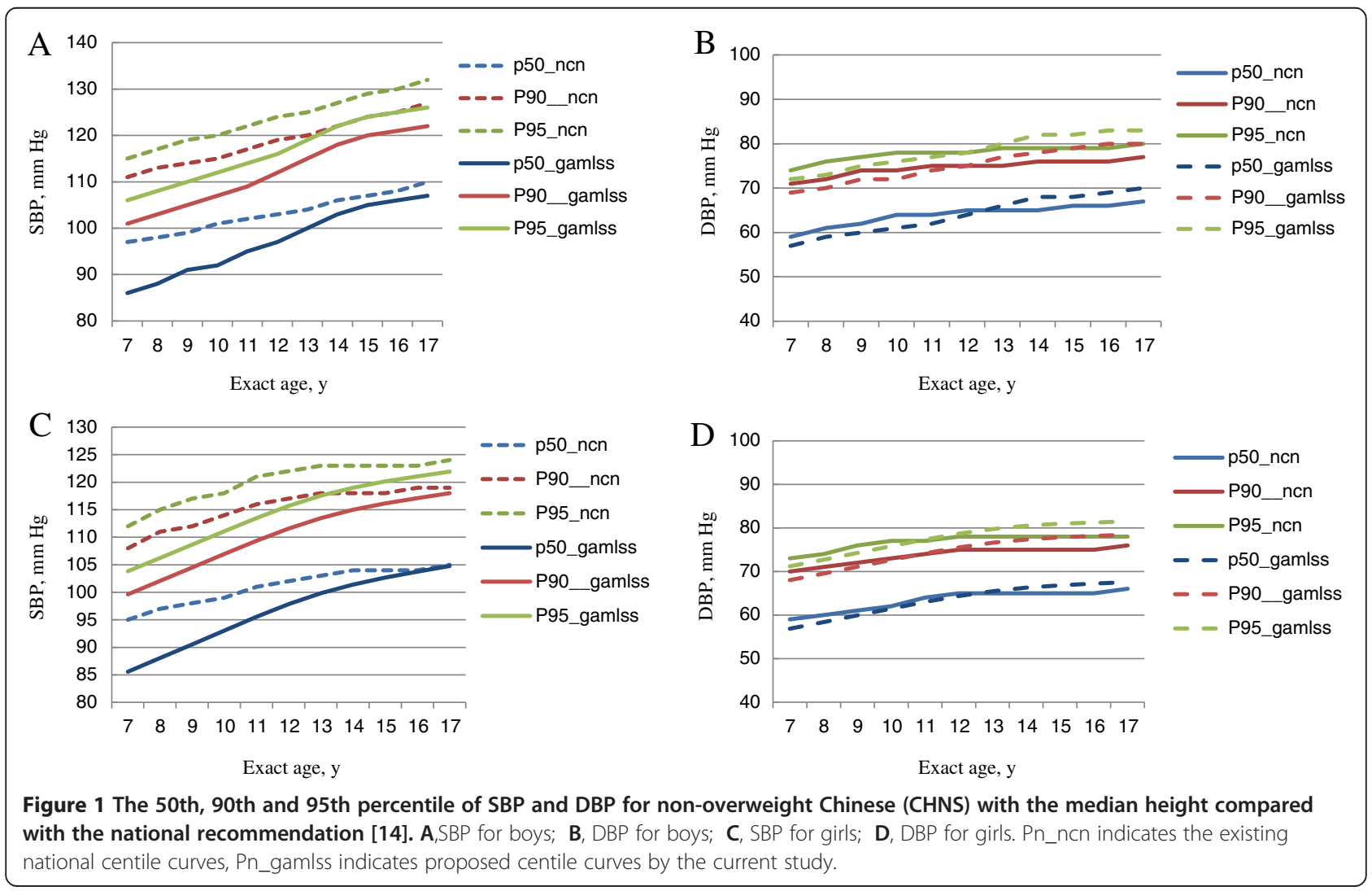




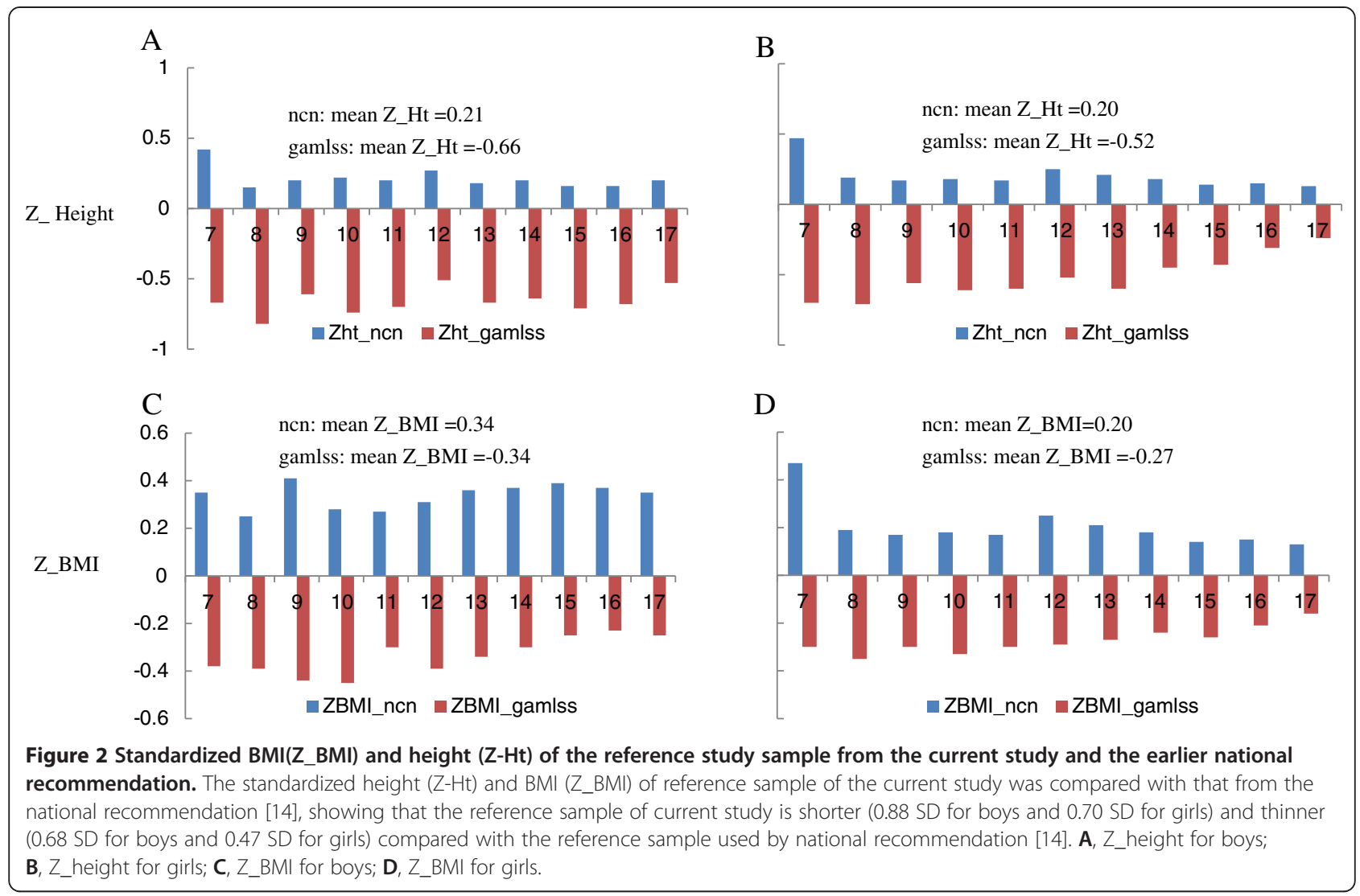

age of 11-12 years but exceeded it up to 17 years old to the similar extent with the age of 7 . This trend remained similar in boys and girls.

\section{Comparison with US national reference tables}

Compared with the international blood pressure table recommended by the Fourth report [13] (Figure 3), the 50th, 90th and 95th percentiles of SBP in Chinese boys and girls were averagely $9-10 \mathrm{~mm} \mathrm{Hg}$ lower than the expected values for the American counterparts; however, there were no clear difference in DBP percentiles.

\section{Discussion}

We present the first height percentile specific-blood pressure references in China and compare these with the earlier ones also international values. These new cutoffs will be more accurate for evaluating blood pressure levels for children and adolescents with extreme heights. The proposed 90th and 95th percentiles of blood pressure may be used to detect prehypertension and hypertension in Chinese pediatric population. The using of nonoverweight reference sample may makes the proposed blood pressure cutoff points more sensitive to identify children with elevated blood pressure because of with risk factors such as being overweight or obese. The 99th percentiles are not proposed based on the thinking that children with blood pressure measurements over it will not be directly diagnosed as hypertension, instead, additional blood pressure measurements will be suggested.

Height is a key covariate associated with blood pressure levels. The ignoring of height of the blood pressure references may result in inaccurate blood pressure evaluation in pediatric practice especially for children who are very short or tall. Since there may be significant difference in height distribution between the current study sample and others, the blood pressure cutoffs for exact height values instead of height percentile categories are proposed to make it more practical and accurate for individual blood pressure assessment.

Compared with the existing national age-specific blood pressure recommendations [14], the blood pressure percentiles for age proposed by the current study were lower. In the earlier recommendations [14], only function of age on blood pressure was considered, the blood pressure percentiles could be understand as the functions of age and average height of the study population. It may be appropriate for those with average height, while it may make inaccurate estimation of blood pressure for children with extreme heights. The current study uses new statistical method GAMLSS model, which is able to handle two and more covariates to allowance to fit functions of both age and height to blood 


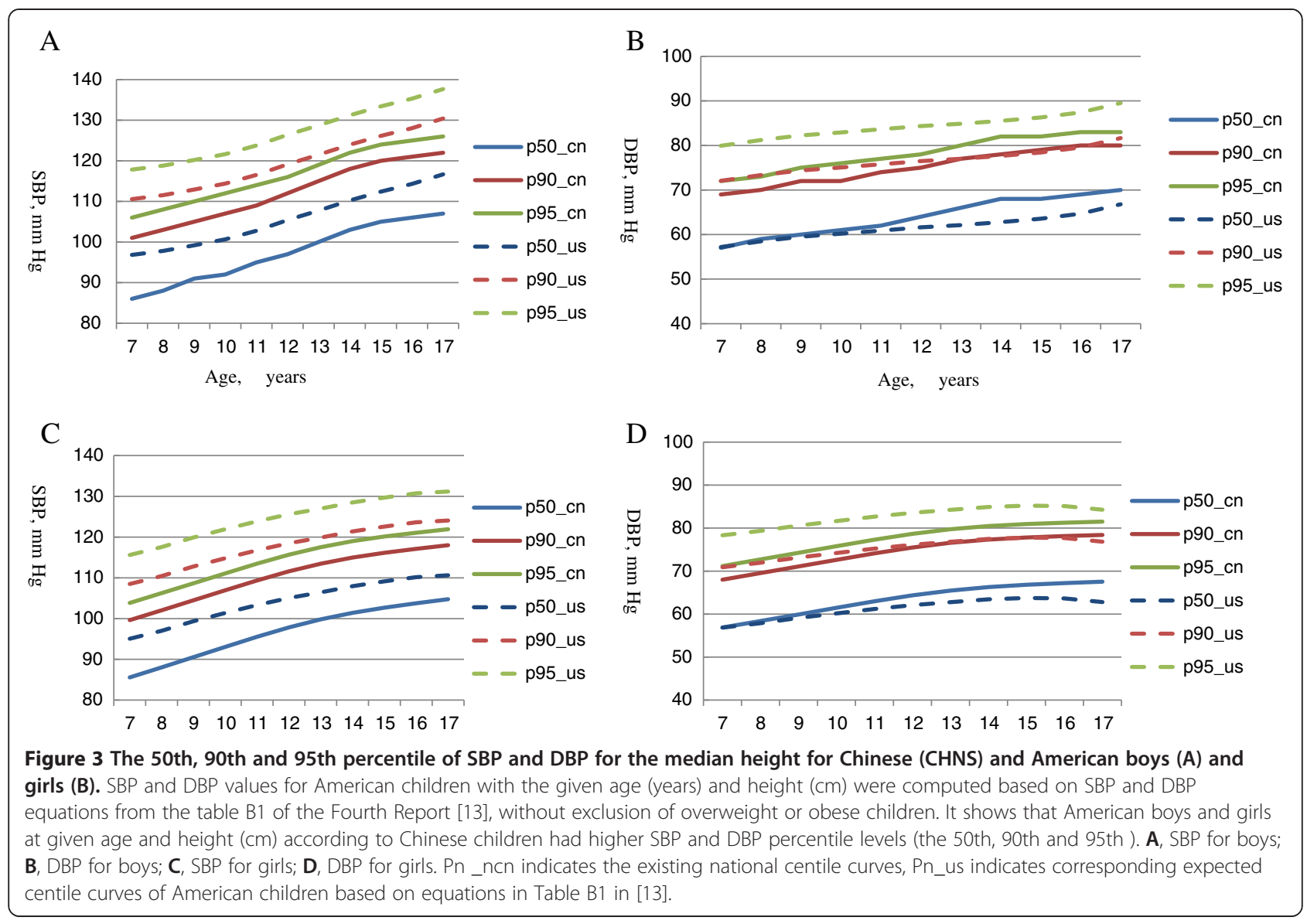

pressure levels. Compared with the earlier recommendation [14], the percentiles proposed by the current study will be more accurate especially for those children with extreme heights. In addition, exclusion of overweight and obese subjects from the reference population of the current study makes lower BMI levels compared with that used by the earlier study (BMI Z-score difference is averagely $0.68 \mathrm{SD}$ for boys and $0.47 \mathrm{SD}$ for girls). The corresponding lower cutoffs of blood pressure we propose are expected to be more sensitive to identify obesity-related high blood pressure in children.

In overall, the blood pressure percentiles we proposed are lower than the international one for American children [13], which also consider both functions of age and height on blood pressure levels. The racial difference of blood pressure reference values for given age and height supports the necessity of establishing blood pressure references for Chinese children and adolescents, in order to achieve early prevention of childhood hypertension in the country.

Given the complex calculations for individual assessment of blood pressure in practice, a Blood Pressure Calculator has been developed based on the fitted models of blood pressure from this study. After inputting age, gender, height, SBP and DBP levels, it will return SBP and DBP percentiles and blood pressure status (normotensive, prehyepertensive or hypertensive). This calculator may greatly help individual clinical evaluation of blood pressure in hospitals and public health settings.

Our study has some limitations. The sample size of boys and girls aged 7-17 years are relatively small compared with the total population of China, and survey fields cover only 7 east coast provinces. However, we choose to use CHNS data is based on the considerations that the CHNS study are jointly funded by Chinese government and American organizations, the methodology of blood pressure measurement, quality control and data management follow international criteria, the international comparisons will be more convincing. Second, no external validation was made to assess the performance of the newly proposed blood pressure tables. A second validation study would be helpful to compare the accuracy of ageand height-specific blood pressure percentiles from nonoverweight reference sample proposed by the current study with the existing age-specific percentiles but without excluding overweight subjects [14] in children's blood pressure assessment. 


\section{Conclusion}

In summary, the current study proposes the first age and height corrected blood pressure percentiles for Chinese children and adolescents aged 7-17 years with potential for more accurate blood pressure evaluation for children with extreme height, and in identifying obesity-related high blood pressure. It is expected that the proposed new references will be used in clinical individual blood pressure evaluation and governmentsupported annual national regular school-based fitness and physical survey in China.

\section{Competing interests}

The authors declare no financial or non-financial competing interests.

\section{Authors' contributions}

AB carried out the molecular genetic studies, participated in the sequence alignment and drafted the manuscript. JY carried out the immunoassays. MT participated in the sequence alignment. ES participated in the design of the study and performed the statistical analysis. FG conceived of the study and participated in its design and coordination and helped to draft the manuscript. All authors read and approved the final manuscript. WY conceptualized and designed the study, supervised the gamlss modeling and all the statistical analyses, drafted the manuscript, and approved the final manuscript as submitted. FL, XL, LW, YZ and YC carried out the conventional statistical analyses, made the tables, reviewed and revised the manuscript, and approved the final manuscript as submitted. WZ and GH participated design, data interpretation, discussion and approved the final manuscript as submitted.

\section{Acknowledgements}

We thank Dr. D. Mikis Stasinopoulos for his kind supervision and help in modeling blood pressure using GAMLSS program.

\section{Funding sources}

This work is supported by Chinese National "Twelfth Five-Year" Plan for Science \& Technology Support (Grant No. 2012BAI03B00); National Natural Science Foundation of China (Grant No. 81273168).

\section{Author details}

'Department of Clinical Epidemiology, Children's Hospital of Fudan University, 399 Wanyuan Road, Shanghai 201102, China. ${ }^{2}$ Cardiac Center, Children's Hospital of Fudan University, Shanghai, P.R. China. ${ }^{3}$ Department of Vascular Surgery, The No 5 Hospital of Shanghai, Shanghai, P.R. China. ${ }^{4}$ Department of Neonatology, Children's Hospital of Fudan University, Shanghai, P.R. China.

Received: 19 June 2013 Accepted: 22 November 2013

Published: 25 November 2013

\section{References}

1. McNiece KL, Poffenbarger TS, Turner JL, Franco KD, Sorof JM, Portman RJ: Prevalence of hypertension and pre-hypertension among adolescents. J Pediatr 2007, 150(6):640-644. 644 e641.

2. Chiolero A, Cachat F, Burnier M, Paccaud F, Bovet P: Prevalence of hypertension in schoolchildren based on repeated measurements and association with overweight. J Hypertens 2007, 25(11):2209-2217.

3. Chiolero A, Paccaud F, Bovet P: Pre-hypertension and hypertension among adolescents of Switzerland. J Pediatr 2007, 151(6):e24-e25.

4. Cui Z, Huxley R, Wu Y, Dibley MJ: Temporal trends in overweight and obesity of children and adolescents from nine Provinces in China from 1991-2006. Int J Pediatr Obes 2010, 5(5):365-374

5. Liang YJ, Xi B, Hu YH, Wang C, Liu JT, Yan YK, Xu T, Wang RQ: Trends in blood pressure and hypertension among Chinese children and adolescents: China Health and Nutrition Surveys 1991-2004. Blood Press 2011, 20(1):45-53.
6. Chen $X$, Wang Y: Tracking of blood pressure from childhood to adulthood: a systematic review and meta-regression analysis. Circulation 2008, 117(25):3171-3180

7. Lauer RM, Clarke WR: Childhood risk factors for high adult blood pressure: the Muscatine Study. Pediatrics 1989, 84(4):633-641.

8. Mahoney LT, Burns TL, Stanford W, Thompson BH, Witt JD, Rost CA, Lauer RM: Coronary risk factors measured in childhood and young adult life are associated with coronary artery calcification in young adults: the Muscatine Study. J Am Coll Cardiol 1996, 27(2):277-284.

9. Berenson GS, Srinivasan SR, Bao W, Newman WP 3rd, Tracy RE, Wattigney WA: Association between multiple cardiovascular risk factors and atherosclerosis in children and young adults. The Bogalusa Heart Study. N Engl J Med 1998, 338(23):1650-1656.

10. Lande MB, Carson NL, Roy J, Meagher CC: Effects of childhood primary hypertension on carotid intima media thickness: a matched controlled study. Hypertension 2006, 48(1):40-44.

11. Zhu H, Yan W, Ge D, Treiber FA, Harshfield GA, Kapuku G, Snieder H, Dong $Y$ : Cardiovascular characteristics in American youth with prehypertension. Am J Hypertens 2007, 20(10):1051-1057.

12. Rademacher ER, Jacobs DR Jr, Moran A, Steinberger J, Prineas RJ, Sinaiko A Relation of blood pressure and body mass index during childhood to cardiovascular risk factor levels in young adults. J Hypertens 2009, 27(9):1766-1774.

13. National High Blood Pressure Education Program Working Group on Hypertension Control in Children and Adolescents: The fourth report on the diagnosis, evaluation, and treatment of high blood pressure in children and adolescents. Pediatrics 2004, 114(2 Suppl 4th Report):555-576.

14. Mi J, Wang T, Meng L, Zhu G, Han S, Zhong Y, Liu G, Wan Y, Xiong F, Shi J, et al: Development of blood pressure reference standards for Chinese children and adolescents. Chin J Evid Based Pediatr 2010, 5(1):4-14.

15. CHNS: China health and nutrition survey: design and methods. http://www.cpc.unc.edu/projects/china/about/design.

16. Liu H: The China health and nutrition survey: an important database for poverty and inequality research. J Econ Inequal 2008, 6:373-376.

17. Popkin BM, Du S, Zhai F, Zhang B: Cohort Profile: the China Health and Nutrition Survey-monitoring and understanding socio-economic and health change in China, 1989-2011. Int J Epidemiol 2010, 39(6):1435-1440.

18. Ji CY: Report on childhood obesity in China (1)-body mass index reference for screening overweight and obesity in Chinese school-age children. Biomed Environ Sci 2005, 18(6):390-400

19. Cole TJ, Green PJ: Smoothing reference centile curves: the LMS method and penalized likelihood. Stat Med 1992, 11(10):1305-1319.

20. Work Group of Physical Fitness and Health Surveillance of Chinese School Students: Report on the Physical Fitness and Health Surveillance of Chinese School Students. Chinese high education press. ISBN: 9787040212006).2007 $\left(1^{\text {st }}\right.$ ed).

21. The IDF consensus worldwide definition of the metabolic syndrome. http://www.idf.org/metabolic-syndrome.

doi:10.1186/1471-2431-13-195

Cite this article as: Yan et al:: Blood pressure percentiles by age and height for non-overweight Chinese children and adolescents: analysis of the china health and nutrition surveys 1991-2009. BMC Pediatrics 2013 13:195

\section{Submit your next manuscript to BioMed Central and take full advantage of:}

- Convenient online submission

- Thorough peer review

- No space constraints or color figure charges

- Immediate publication on acceptance

- Inclusion in PubMed, CAS, Scopus and Google Scholar

- Research which is freely available for redistribution 